\title{
Health concerns and use of biomass energy in households: voices of women from rural communities in Western Uganda
}

\author{
Juliet Kyayesimira ${ }^{* *}$ and Florence Muheirwe ${ }^{2}$
}

\begin{abstract}
Background: Over the years, there has been advocacy for use of improved cookstoves as one of the initiatives towards reducing overdependence on biomass energy. There is growing concern that the use of biomass energy may expose users to pollution which may be detrimental to their health. This study aimed at examining the health concerns of women attributed to access and use of biomass fuel in rural areas of Western Uganda.
\end{abstract}

Methods: A cross-sectional study design was employed where 193 respondents and 10 key informants participated in the interviews. Four focused group discussions were held in the districts of Mbarara and Bushenyi in Western Uganda. Quantitative data were analyzed using the Statistical Package for Social Sciences, while qualitative data were analyzed using the thematic approach.

Results: Dependence on biomass energy may expose users especially women to both physical and psychological health challenges. Findings suggest that the type of cookstove and cooking structure contribute to indoor air pollution. Women are exposed to pollution while preparing meals using biomass fuel which may lead to respiratory complications and other health-related challenges. Additionally, while gathering biomass fuel, women may be exposed to other risks and hazards that may lead to poor health and or trauma.

Conclusion: It is crucial for different stakeholders from both the public and private sectors to promote use of improved cookstoves through sensitization programs, promotional campaigns, and development of supportive regulatory frameworks for the well-being of women and their families.

Keywords: Health, Biomass energy, Women, Uganda

\section{Introduction}

Biomass energy is predominantly used in traditional cookstoves in most homesteads in developing countries. It is estimated that almost half of the world's population use biomass energy for various activities such as cooking, heating and lighting $[1,2]$. The dependence on biomass energy is predicted to continue rising especially in

\footnotetext{
*Correspondence: kyayejue@gmail.com

${ }^{1}$ Department of Biology, Kyambogo University, Kyambogo, P.O. Box 1, Kampala, Uganda

Full list of author information is available at the end of the article
}

developing countries. This is because of overdependence on wood and charcoal as sources of fuel [3]. Nearly 3 million people are users of biomass fuel for cooking globally and $80 \%$ of these are from sub-Saharan Africa [4-6]. This is estimated to continue rising and may surpass fuel use in other regions such as Latin America and Asia. Predictions indicate that by 2030, nearly 1 billion people, specifically from Africa, will still rely on traditional biomass to meet their energy needs [6], which will create a shortage of fuel for cooking because of deforestation. Overdependence on biomass energy by traditional cookstove users may have consequences on health. otherwise in a credit line to the material. If material is not included in the article's Creative Commons licence and your intended use is not permitted by statutory regulation or exceeds the permitted use, you will need to obtain permission directly from the copyright holder. To view a copy of this licence, visit http://creativecommons.org/licenses/by/4.0/. The Creative Commons Public Domain Dedication waiver (http://creativecommons.org/publicdomain/zero/1.0/) applies to the data made available in this article, unless otherwise stated in a credit line to the data. 
The use of traditional cookstoves contributes to pollution of the household and the environment, which may lead to poor health outcomes for people vulnerable to the exposure. This is because traditional cookstoves predominantly rely on the use of biomass energy such as wood, charcoal and dung which generate a lot of emissions into the atmosphere [7, 8]. Notably, this may affect the respiratory health of not only the users but the occupants of the homestead in general $[2,9]$. Some of the morbidity and mortality occurrences are attributed to inhalation of fine particulate matter which emanates from cookstove-related pollution [10]. However, there is a debate on whether only traditional cookstoves may lead to health consequences. Some scholars have argued that both traditional cookstoves and Improved Cookstoves (ICS) produce emissions and thus it may be misleading to conclude that using traditional cookstoves has more risky concerns [8, 11]. Regardless of this debate, the World Health Organization (WHO) report estimates that 4.3 people die because of exposure to household air pollution emanating from exposure to smoke from traditional cookstoves and open fires [12, 13]. It is also estimated that $\$ 123$ billion of money is lost to cater for the effects associated with the dependence on solid fuels [14]. This is lost to address consequences of poor health outcomes, depletion of natural biomass sources, environmental degradation and associated impacts.

A number of health complications are attributed to cook-fire smoke and affect mostly women and children. Women, girls and children are at a greater risk because they spend more time keeping close to cooking points while fulfilling domestic gender roles of preparing food for the household using inefficient cookstoves [6, 9]. Some of the poor health outcomes from this exposure include chronic illnesses and acute health impacts such as early childhood acute lower respiratory infections (including pneumonia), which lead to mortality, low birth weight, and associated long-term adverse health impacts [10]. For adults, the smoke can lead to long-term risks and mortalities from lung cancer, emphysema, chronic obstructive pulmonary disease, cataracts, bronchitis and adverse pregnancy outcomes [14]. More so, minor ailments from daily smoke inhalation may include eye irritation and headaches [15]. While the stipulated health outcomes are attributed to exposure to the pollution generated by the use of biomass energy, there are other health outcomes beyond the effect of pollution.

The process of accessing biomass fuel also poses some physical and psychological trauma for women and their household members. While collecting firewood, women may get physical injuries as well [14]. Besides physical health, women may be subjected to safety and security hazards while gathering biomass energy and this may lead to stress and depression [14]. For instance, women may be confronted with dangers of sexual violence and life-threatening attacks, exposure to wild animals or reptiles [6]. In certain areas, local sources of firewood are completely depleted, leading women to travel long distances and spend long hours gathering firewood. This reduces the time spent caring for the homesteads and feeding of children which can lead to nutritional deficiencies [6]. Women may also be tempted to exchange sex for wood fuel [6], which also may further complicate their lives with sexually transmitted infections. This may also contribute to Gender-Based Violence (GBV) due to spouse accusations of unfaithfulness, but also due to failure to bring home firewood to meet the expectation of preparing meals for their families $[6,16,17]$.

Other health-related effects are the energy accessibility constraints. In areas where forest cover and trees are getting depleted, this may have a negative impact on the quantity, quality and nutritional value of the food consumed in households. Some homesteads may resort to undercooking meals (inadequate food preparation) in order to use less fuel $[12,18]$, reducing the quality of food $[6,18]$ which could result in less healthier foods and poor diet intakes [19]. This may contribute to domestic violence for failure to prepare timely meals due to inadequate energy resources [18]. Skipping some meals or even opting for foods with less time for cooking may be another decision taken which may be a barrier to more healthy diets [19]. Reliance on energy natural resources contributes to depleting of the natural resources and destroying of the environment, which contributes to climate change that affects agriculture [6], consequently compromising the nutrition quantity and quality of food consumed by households.

Extensive studies have been conducted focusing on the use of biomass energy, traditional cookstoves and ICS. Some of the studies measured the pollution concentrates emanating from the use of biomass fuel in households $[11,20-22]$ and others focused on the health implications $[18,22-24]$. There are studies showing that emissions from both traditional cookstoves and ICS pose health risks to human beings $[8,11]$. Quite a number of studies have focused on the adoption and usage of improved cookstoves [9, 18, 20, 25-28]. Improved cookstoves are efficient, use less biomass fuel and release limited emissions when cooking, unlike traditional stoves. There are also studies that explore access to energy resources and female empowerment [29, 30]. In Uganda, a few studies conducted focused on charcoal, wood fuel utilization and related impact on the environment [31, 32]. Some scholars reviewed the general energy situation in Uganda focusing on demand and supply, as well as future predictions $[33,34]$. While some studies have focused on the 
development of bioenergy technologies [33, 35, 36], others have studied deforestation and related biomass fuel changes in Uganda and implications for health [31, 37]. Some of the studies reviewed acknowledge the negative impact of the use of biomass in households [38-40], however, they do not specifically take into consideration the perspectives of women. By recognizing the strength and limitations of previous studies conducted, the main purpose of this study was to examine the health concerns of women in regard to access and use of biomass fuel in the rural areas of western Uganda through capturing the voices of women's experiences. In doing so, the study is premised on two research questions: (1) What are the health concerns of women using traditional biomass cookstoves? (2) Why do women fail to easily adopt to the use of ICS despite the health consequences associated with use of traditional cookstoves? This study offers critical insights into the perspectives of women regarding health dimensions associated with access and utilization of biomass energy in rural areas, and contributes to the growing body of literature on energy and resource use. It also contributes to the debate on the impact of ICS on health and advocates for the improvement of cookstoves and cooking spaces, as well as alternative sources of energy for the rural communities. "Introduction" section of this paper presents the introduction to the study, "The ecological theory: implications for biomass energy and health" section explains the theoretical underpinnings of the study, "Methods" describes the methodology used, and "Results" section presents the findings, while "Discussion" section discusses the findings. "Conclusion" section presents the conclusions from the study and highlights the recommendations

\section{The ecological theory: implications for biomass energy and health}

This paper applies the Ecological Theory of Bronfenbrenner, 1992. A range of factors influence behavior including the use of biomass, so, if we want to understand why the use of biomass remains dominant despite the health issues, or if we want to change overdependence on biomass, it is important to have a framework. The ecological theory outlines a hierarchy of five aspects that include behavior [41]. These include: intrapersonal/individual, interpersonal, institutional/organizational, community and public policy factors. Intrapersonal/individual factors include aspects such as knowledge, attitudes, beliefs, and personality, while interpersonal factors consider the interaction between and among people [41].Institutional and organizational factors include rules, regulations, policies, and informal structures, while community factors encompass formal or informal social norms at an individual, group, or organization level. Public policy focuses on all policies from the lowest to the highest administration unit in society.

Use and access to biomass energy contribute to physical, emotional and environmental health complications. It is the leading cause of household air pollution [42] which may lead to poor health outcomes for those vulnerable to the exposure [38, 42]. Almost a quarter of global deaths and disease burden are attributed to indoor air pollution [42]. Overdependence on traditional cookstoves and reliance on biomass energy have been acknowledged as contributing to indoor pollution and airborne illnesses in most developing countries [22, 23]. One scholar stresses that pollution in all forms and sources including indoor cannot be alienated from the environment and cautions that while addressing indoor pollution, it is important to examine other physical and social dimensions, and how they interact [43]. Environmental health is influenced by environmental factors which determine the physical, mental, and social well-being of people [44]. The environment is diverse and may include the physical and social aspects, but also, how this affects individuals varies in regard to quality and immediacy or exposure [43]. It has been noted for instance, that women and girls are more exposed to indoor pollution than other members in the household [6, 9].

Access to biomass energy in rural communities has also contributed to health consequences of women. There is concern that access to biomass energy has increasingly become scarce and is vulnerable to depletion [6]. The ecological model may be applicable in situations where resources are limited or unequally distributed in the community so as to enable more equitable access for people to meet their daily need and control their lives [45]. As previously discussed, while looking for firewood, women have been exposed to physical and psychological injuries, stress and trauma [6, 46]. The physical environment may not only be a threat to health in terms of toxicity but can also pause injurious conditions and may be a source of danger if looked at in different dimensions [43]. Stokols sums it up that:

\section{'.. people's biological, behavioral, and sociocultural needs and the environmental resources available to them is a key determinant of well-being' [44].}

The ecological model informs this study particularly in regard to the health implications attributed to use and access to biomass energy. In households and at an individual level, knowledge, attitudes, beliefs and personality may determine access to energy, the type of energy source and how it is used. At the same time, interaction in the community especially in a rural setting where individualistic tendencies are shunned, this may enable or constrain adoption to other alternative sources of energy. Rules, 
regulations and policies that are in place by relevant institutions, whether formal or informal may also determine how communities may access sources of energy and who is more vulnerable to air pollution. For instance, due to community values and social norms, women and children bear the burden of collecting firewood and are vulnerable to air pollution because they spend more time preparing meals for the household [9].

The ecological model facilitates the understanding on how individuals in a community may be affected by norms and values in their interactions [47]. In communities, social conditions are vital because they determine the distribution of and access to resources and power, which may determine the ability to meet daily needs [45]. Ultimately, public policies especially in health-related concerns may regulate or support health actions and practices for disease prevention, early detection, control and management of airborne illnesses that emanate from indoor pollution. Policies may target protecting the environment, promoting the quality of public health and safety of the community [43]. It has been noted that the social-ecological model can be used to make structural changes in policy revision or development and the environment [45]. This study resonates with the ecological model because it focuses on the health implication of access and use of biomass energy in rural communities. It explains the interdependence and interaction of multiple factors in relation to specific health problems, but also highlights the significance of people's interactions in their physical and social-cultural environments [45]. It denotes that health issues may not be solved with medication without considering behaviors and environmental components. In communities, specific behavior and roles influence well-being [43]. In that regard, the model argues that in health promotion and awareness-related programs, social-ecological factors are integrated to promote public health and well-being [43].

\section{Methods}

\section{Study sites}

The research was carried out in two districts of Uganda, namely: Mbarara and Bushenyi in the Western region. In Mbarara district, the study area covered 20 villages, while in Bushenyi district, 18 villages were selected. The villages in the districts were selected because they had a number of households that had previously purchased improved cookstoves. This was based on the database provided by the cookstove distribution company in the region. Households were selected randomly from a list of households obtained from the cookstove distribution company. The sample size was determined by the Taro Yamane formula [48] indicated below.

$$
n=\frac{N}{1+N(e)^{2}},
$$

where $n=$ the sample size, $N=$ population size (373), $e=$ the acceptable sampling error at $95 \%$ confidence interval. This formula was chosen because the study was targeting a finite population that included ICS users and potential customers as per the list obtained from the cookstove distribution company.

\section{Study design and selection of participants}

The study undertook a cross-sectional study design, and a mixed methods approach was employed. The study units were households that were using efficient cookstoves commonly called improved cookstoves, and some that were not but were seen as potential customers. In these households, only women were chosen to participate in the study since they are the ones who engage in cooking. The study was interested in the ICS users because it was necessary to understand why they had chosen to adopt to the use of ICS. The non-ICS users were considered because they were deemed more exposed to pollution given the fact that they were predominantly using traditional cookstoves and hence would provide more views on the health concerns related to use of biomass fuels. A total of 193 households $(N=193)$ were selected randomly to participate in this study and out of these, 143 were ICS users while 50 were non-ICS users. Two (2) Focused Group Discussions (FGDs) were conducted in each district with 10-15 participants. Key informants (10) who included four Local Council members, four opinion leaders and two sub-county Development Officers were purposively selected. Village chairpersons assisted the researchers in the identification of opinion leaders. Key informants were critical for affirming issues on access to energy sources in the community and the embedded challenges.

\section{Data collection methods}

An interview guide was developed that enabled the collection of perceptions from the households on the use of ICS and traditional stoves in relation to health implications. It also enabled getting views of households on kitchen and cookstove types because these may have consequences on household health, resulting from the air pollution. The interview guide facilitated the collection of information on the household's understanding of the positive attributes of ICS. Interviews were conducted in the predominant local language (Runyankore) of the respective study areas. The interview sessions lasted between 30-45 min and were held in the evenings at the homesteads, so as not to disrupt the respondents' day plans. A key informant interview 
guide was also used to get views regarding the adoption of cookstoves and access to biomass fuel in the communities. These interviews were conducted at venues suggested by residents at their own convenient time. A focus group discussion guide was designed to facilitate the flow of discussion and interaction. The discussion was focused on getting views on health concerns related to cookstoves and biomass fuels in communities. Information covered ranged from types of energy sources and health-related challenges faced while accessing these sources. Discussions also captured views on the types of cookstoves and the reasons for adopting a particular type. The data collection period for this study spurned from April 2018 to January 2019.

Observation was also employed as a key tool to establish if households were using the improved cookstoves or not, as well as to examine the state of the cooking spaces. The researchers sought permission from the respondents to inspect their cooking spaces and facilities. In this exercise, using a checklist, the researchers observed the types of stoves in the kitchen cooking area and if the ICS appeared to have been recently used (checking if the stove was warm by touching or had ashes or embers inside or if there was soot around the fuel chamber). Literature was also reviewed to understand and comprehend the health concerns related to biomass use and its implications to the household members. Crucial documents by different organizations which included WHO, Global Alliance for Clean Cookstoves, FAO's SAFE frame Project reports were reviewed, among others.

\section{Data analysis}

Quantitative data were analyzed using the Statistical Package for Social Sciences (SPSS) version 20 (IBM Corp. Armonk, NY: Released 2011), and Sigma plot Version 14 was used to draw the graph. Frequencies and percentages were worked out for meaningful interpretation of results. Qualitative data were analyzed using the thematic approach where common themes were categorized, coded and interpreted for meaning.

\section{Ethical consideration}

Permission to conduct this study was sought from the Chief Administration Officers (CAOs) of each participating district and in the respective villages, the researchers introduced themselves to the Local Council leadership structures. Respondents in this study were also informed about the aim of the study and how their views would contribute to the outcomes of the study. Participants were given the liberty to choose whether to participate or not, without any incentives. After the informed consent was sought verbally, respondents also consented to participate in the study without any written agreement.

\section{Results}

To understand the use of biomass energy and its implications for health, perspectives of women from rural areas were gathered. In this section, socio-demographic features are presented first and this is followed by the categorized themes, namely: kitchen and cookstove types, benefits of improved cookstoves and adoption, access to biomass fuel and associated health risks, as well as health concerns of using traditional cookstoves.

\section{Socio-demographic characteristics of respondents}

Socio-demographic characteristics were sought to understand the respondents in the study. Level of education and household income were the only considered vital socio-demographic characteristics for this study. This was informed by the study in Ethiopia which found out that heads of literate households are more likely to adopt improved cookstoves and that the increase of household income may influence the uptake of ICS [49].

Education level may for instance lead to increased opportunities for jobs and income and hence enhance capacity to access efficient cookstoves and different types of energy sources probably with lesser health risks. Secondly, education may raise awareness about indoor pollution. Household income may facilitate households to acquire different types of energy technologies and to construct a better cooking structure or space.

\section{Respondents' level of education}

As indicated in Table 1, there was a high level of literacy among the respondents, with only $5.7 \%$ of the respondents lacking formal education and $1.6 \%$ not willing to disclose their education levels. More than $28 \%$ of the respondents had acquired university education. Findings reveal that the majority (90\%) of the respondents had acquired some level of education. Although the study was conducted in rural areas, it was surprising to have such a number of university graduates. However, this was understandable because Mbarara and Bushenyi are model districts with high levels of literacy according to the Uganda National Bureau of Statistics [50]. This was reaffirmed by the development officers at the sub-county as one of them echoed:

... "You know Bushenyi is referred to as a model district. Most families in the rural areas have managed to send children to school because they recognise the 
Table 1 Weekly household income and level of education of respondents

\begin{tabular}{lllll}
\hline$\#$ & Household income (UGX) & Percentage (\%) & Level of education & Percentage (\%) \\
\hline 1 & Less than 10,000-30,000 & 18.8 & No formal education & 5.7 \\
2 & $31,000-50,000$ & 28.7 & Primary education & 15.5 \\
3 & $51,000-100,000$ & 14.0 & Secondary education & 24.4 \\
4 & $101,000-150,000$ & 5.6 & Trade/vocational school & 24.4 \\
5 & 150,000 and above & 6.3 & University & 28.5 \\
6 & Not disclosed & 26.6 & No response & 1.6 \\
& Total & 100 & & 100 \\
\hline
\end{tabular}

importance of education. You see when a person is educated, their level of reasoning cannot be compared to a person that has never been to school".

Given the high level of literacy in the area, it was not surprising that there were homesteads that had already adopted the use of ICS.

\section{Household income of respondents}

Table 1 demonstrates that $28.7 \%$ of the respondents were able to spend between 30,000 and 50,000 Ugandan shillings, while very few $(6.3 \%)$ were able to spend more than 150,000 Ugandan shillings. Some of the respondents $(26.6 \%)$ were not willing to disclose their weekly income expenditure. Nonetheless, the income ranges depict that the participants were above the average poor when compared to most rural communities [51]. The study probed further to understand the participants' various sources of income. Although this was a rural setting, the majority of the respondents $(60 \%)$ were mainly salaried (either working with schools, health centers or local government structures) as indicated in Fig. 1. Respondents revealed that they did not rely on government salaries which were not only inadequate, but also delayed to be paid.

Some of the households (10\%) were engaged in farming (livestock and poultry), in addition to their main source of income. It was observed that cows and goats were the common types of livestock in the area. As indicated in Fig. 1, the study reveals that homesteads

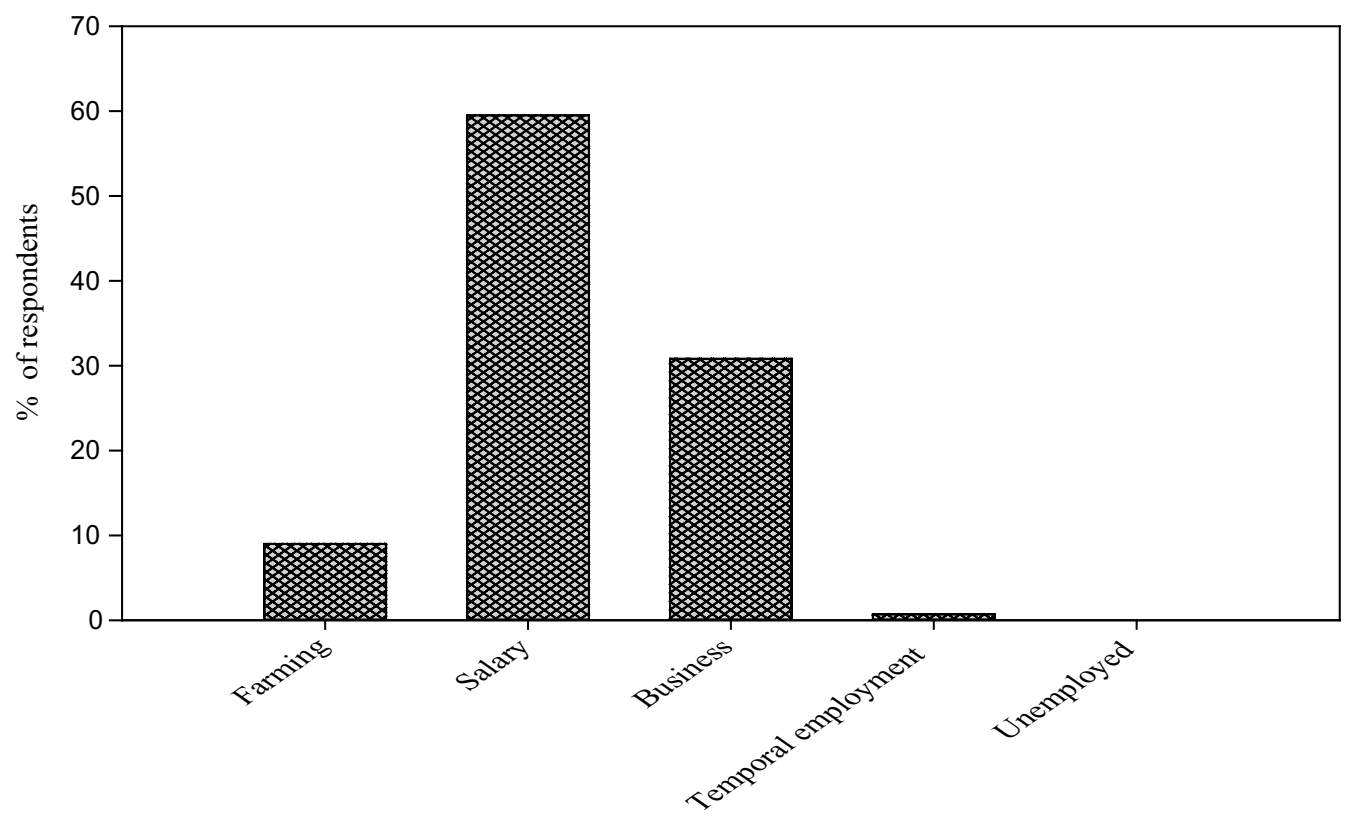

Source of income

Fig. 1 Participants sources of income 
had multiple sources of income. In this regard, it could be presumed that households have the capacity to meet most of their needs including biomass energy.

\section{Types of kitchens and cookstoves in households}

The nature of kitchens and the type of cooking facilities gives an indication of the extent to which homesteads may be exposed to indoor pollution. Cooking spaces and the types of cooking stoves were thus observed in this study. It was noted that respondents had at least a kitchen where they were preparing most of the household meals. The kitchen structures were either enclosed or open shift structures, while some few respondents cooked from the veranda of the houses in which they slept. The cooking spaces and structures observed were susceptible to smoke congestion and indoor pollution. This was also worsened by the use of wet firewood that emits a lot of smoke while cooking. One of the respondents lamented that:

My kitchen does not have windows and the ventilators are very small, now my whole kitchen is covered with soot. Wood in this village is very scarce. So, sometimes, I collect and use wet firewood which produces a lot of smoke.

These revelations could indicate that communities have not been sensitized on indoor pollution and the importance of a good cooking environment and space.

Respondents who were ICS users (143) revealed that they were using both traditional and improved cookstoves. When probed why they were still using traditional cookstoves, respondents revealed that they were accustomed to these stoves and it was difficult to eliminate them. Some of the respondents noted that because ICS cooks faster, the food is not as tasty as when one uses a traditional cookstove. These claims and concerns may limit the adoption of ICS.

The study indicated that the usage of the 3-stone fire (traditional cookstove) was common before the purchase of the ICS by the households but they still used the 3-stone fire when cooking multiple dishes. In the group discussions, women who had not purchased the ICS, revealed that the stoves were quite expensive to purchase. Such notions could be attributed to personal beliefs and attitudes that individuals hold without considering the future state of affairs regarding the scarcity of wood fuel. However, as individuals interact within the community, some of these beliefs are shared and in the absence of sensitization programs, they may become shared values.

\section{Benefits of improved cookstoves and adoption}

For the communities to adopt ICS, they must attach benefits to using them. In this study, we were interested in examining whether respondents could identify particular attributes of ICS. Respondents acknowledged that the ICS was expensive to acquire but in the long run enables the homestead to save on wood fuel expenses and minimize on the health risks associated with routinely collecting wood fuel. Forty nine percent (49\%) of the respondents revealed that traditional cookstoves consume more biomass fuel and thus more expenditure on fuel, $16.8 \%$ thought there was no difference on the fuel expenses between traditional cookstoves and ICS, while $34.2 \%$ were not sure of any significant differences. From the group discussions held, participants thought that the ICS used less fuel and their views are indicated in Box 1.

Box 1 Reasons why ICS have less fuel consumption

- Once the ICS heats up, it cooks so fast and therefore food gets ready within a short time

- The way the ICS was made, it is very efficient. You can only put little wood at a time and it is always adequate to prepare a meal, unlike the traditional cookstoves where you have to use many logs of firewood

-Whereas in the traditional cookstoves the fire burns out, once one has finished cooking, the ICS retains heat and this can be used to warm food or to prepare light meals or boil water

Additionally, respondents who were using ICS noted that the stoves were safe to use because they are clean and do not heat up on the outside surface. On the other hand, it was narrated that while cooking with traditional cookstoves, you have to keep fanning and so the whole kitchen gets littered. One of the respondents who had a bad ordeal with traditional cookstoves narrated:

'I have never been burnt while using my ICS but with my traditional cookstove, sometimes when blowing the fire to light up, sparks can spread in the entire kitchen and if you are not careful when they fall on your body or clothes, you get burns. That is why I purchased this ICS.

Revelations clearly indicate that traditional cookstoves do not guarantee 'clean and safe cooking' and that ICS are more likely to be preferred. Thus, the benefits deriving from the usage of ICS have the potential to influence sustained use and adoption.

\section{Access to biomass fuel and associated health risks}

In this study, it was vital to establish the ease with which respondents were able to get biomass fuel for the homestead needs without putting their lives at risk. Respondents explained that because the use of traditional cookstoves requires a lot of wood fuel, it exposes them to many health-related risks while collecting firewood in the 
community. In the focus group discussion, it was revealed that firewood had become scarce in the recent years compared to 15 years back. Participants explained that more than 10 years back, the village had thick bushes called 'orugando' (Acacia hockii De Wild.), where women and children would collect firewood. It was still risky because there would be venomous snakes and wild dogs in these bushes. Over the years, almost all bushes have been cleared for agricultural activities, participants revealed. Some households were trying to plant their own trees for firewood. Those without adequate land on which to plant their own trees had to find a way of accessing fire wood either by buying or walking longer distances. Respondents revealed that while collecting firewood in the hills, they were bitten by stinging insects, sometimes snakes and they also got scratched and wounded by shrubs or even get raped. One of the respondents summed it up by revealing that:

Collecting firewood far away from home is very risky especially for women. Recently, there was an incident where one girl from this village was attacked and raped while collecting firewood. Most of us as mothers, we are worried for ourselves and our daughters since collecting firewood is normally done by women and girls.

This is quite sad because victims may contract sexually transmitted diseases, get unwanted pregnancies but more so, become traumatized.

Some women accessed wood fuel by encroaching on other community members' tree plantations, it was revealed. It was noted that there were rising conflicts over firewood and tree encroachment in the community. In the interview with local leaders, it was noted that in their dispute and conflict resolution meetings, illegal encroachment on fire wood and trees by some members was common. During focus group discussions, it was mentioned that this was also shameful and stressing for the women that had been accused of encroachment.

To reduce on chances of such disputes and the risks associated with looking for firewood, women had resorted to preparing light meals, which consume less wood fuel, while foods such as dry beans and peas which take a longer time to cook were prepared once a week. More so, households avoided cooking every day by preparing meals that lasted a few days. It was revealed that sometimes food went bad since it was not refrigerated which put household members at the risk of food poisoning as one participant voiced out.

In my household I cook beans for the whole week but I keep warming them every day. Unfortunately, sometimes they tend to get spoiled but we consume them because we cannot afford wastage of food. When you think of cooking beans again and the time it takes and the wood fuel needed, you just have to wash the spoiled beans and boil them for your next meal. Some times when my children consume such food, they complain of stomach upsets and gas bloating.'

The discussion indicates that access to biomass fuel is limited in the study area. Strategies and coping mechanisms have thus been adopted such as preference for fast cooking foods. This might affect the nutritional status of the food thereby compromising family health.

\section{Health concerns attributed to the usage of traditional cookstoves and biomass fuel}

The focus of this study was to examine health concerns that may be attributed to the usage of biomass fuel which is predominately used in traditional cookstoves. From the study findings, there seems to be a consensus that traditional stoves were smokier than ICS. The majority of the respondents $(67.8 \%)$ mentioned that they had never felt headache while using ICS nor traditional stoves. Likewise, the majority $(69.2 \%)$ of the respondents indicated that they had never had difficulty in breathing while using ICS or traditional stoves. However, more than 5\% of the respondents had suffered some form of discomfort while utilizing traditional cookstoves either by having difficulty in breathing, frequent headaches or coughing. Although the number appears insignificant, this should not be ignored. Probably the respondents had afflictions that they could not directly attribute to indoor pollution due to lack of awareness as one participant revealed:

.... I think I have an allergy because whenever I use firewood that is not very dry and the kitchen gets filled with smoke, I normally cough endlessly. Some nights I go to bed with a terrible headache and a running nose and I presume that I am suffering from flue but in the morning, I wake up very normal without any ailment.

On the other hand, these revelations could be attributed to the long time spent exposed to smoky kitchens, but also the fact that households had enclosed kitchens without adequate ventilation as was observed.

Some respondents as indicated in Table 2 revealed that they experienced itchy eyes and burns while cooking with traditional cookstoves compared to ICS. Although this was not a very significant number, it cannot be ignored.

Respondents were asked whether they were aware of indoor pollution caused by the usage of inefficient cooking stoves. There seemed to be agreement that traditional cookstoves emitted a lot of smoke compared to ICS. One 
Table 2 Health and well-being of respondents using ICS and traditional stoves

\begin{tabular}{|c|c|}
\hline \multicolumn{2}{|c|}{ Frequency of headaches while using ICS compared to time before when using traditional stoves } \\
\hline More often & $4(2.8 \%)$ \\
\hline Less often & $36(25.2 \%)$ \\
\hline About the same frequency & $6(4.2 \%)$ \\
\hline I never have headaches & $97(67.8 \%)$ \\
\hline \multicolumn{2}{|c|}{ Difficulty breathing while using ICS compared to traditional stoves } \\
\hline More often & $2(1.4 \%)$ \\
\hline Less often & $38(26.6 \%)$ \\
\hline About the same frequency & $4(2.8 \%)$ \\
\hline I never have trouble breathing & $99(69.2 \%)$ \\
\hline \multicolumn{2}{|c|}{ Attack of coughing while using ICS compared to traditional stoves } \\
\hline More often & $4(2.8 \%)$ \\
\hline Less often & $36(25.2 \%)$ \\
\hline About the same frequency & $3(2.1 \%)$ \\
\hline I never have attacks of cough & $100(69.9 \%)$ \\
\hline \multicolumn{2}{|c|}{ Physical comfort while cooking on ICS compared to traditional stoves } \\
\hline More often & $98(68.5 \%)$ \\
\hline Less often & $18(12.6 \%)$ \\
\hline The same & $27(18.9 \%)$ \\
\hline \multicolumn{2}{|c|}{ Burning self while cooking with ICS compared to traditional stoves } \\
\hline More often & $5(3.5 \%)$ \\
\hline Less often & $20(14.0 \%)$ \\
\hline About the same frequency & 0 \\
\hline I never burn myself & $118(82.5 \%)$ \\
\hline \multicolumn{2}{|c|}{ Experience itchy eyes while cooking with ICS compared to traditional stoves } \\
\hline More often & $6(4.2 \%)$ \\
\hline Less often & $47(32.9 \%)$ \\
\hline About the same frequency & $4(2.8 \%)$ \\
\hline I never have itchy eyes & $86(60.1 \%)$ \\
\hline
\end{tabular}

of the respondents who was using both ICS and traditional cookstoves explained:

'Whenever I use the traditional cookstove, it produces a lot of smoke which spreads in the entire kitchen ... this causes my eyes to tear but when I use the ICS, the smoke is limited and my eyes don't get affected.'

It should be noted that women being the ones responsible for preparing meals as indicated in this study, may be vulnerable to the exposure to indoor pollution. Respondents were worried that the pollution also affects their children whom they carry to the kitchen while cooking and the girl children whom they sometimes delegate to complete some cooking tasks. This demonstrates that respondents were aware of the difference between the usage of ICS and traditional cookstoves. Notably, the findings as presented in Table 2, do not indicate significant variations in health benefits associated with the use of ICS and traditional cookstoves.

\section{Discussion}

This paper aimed at examining the health concerns attributed to the access and use of biomass fuel in rural areas of Western Uganda. Perspectives of women using traditional cookstoves and ICS were sought and this was complemented by observation and review of the relevant documents. The discussion below revolves on the generated themes that were presented in "Results" section. These include: social-demographic characteristics of respondents, kitchen and cookstove types, benefits of ICS and adoption, access of biomass fuel and the associated health risks as well as the health concerns of using traditional and improved cookstoves.

The types of cookstoves used as well as kitchen structures as revealed in this study may contribute to smoke emissions that lead to indoor air pollution. This is also affirmed by other scholars. Some of the studies conducted in Uganda showed that, indoor pollution is exacerbated by the use of biomass fuel and inappropriate congested enclosed cooking spaces [26, 52, 53]. It 
is noted that the type of stove particularly traditional cookstoves consume large amounts of wood fuel and emit a lot of smoke which engulfs households and that the smoke is one of the potential causes of lung diseases and deaths in developing countries [2, 6]. MacCarty et al. observed that personal exposure to emissions vary from one household to another [21]. This could be true since the types of cookstoves and kitchens structures in homesteads also differ. In this regard, it is crucial to have both an improved cookstove in an adequately ventilated kitchen in order to reduce exposure to smoke to protect household members.

Access to biomass fuel contributes to health risks that affect most especially women in rural areas. This study revealed threats to the physical and mental health of women while collecting firewood. There seems to be a consensus among scholars that the burden of collecting firewood rests upon women who are exposed to several risks such as physical injuries and snake bites as well as threats of sexual violence $[6,16,17]$. The health of women may be compromised in different perspectives and dimensions as well. For instance, failure to prepare a family meal in time due to lack of access to biomass fuel contributes to domestic violence [18], which could have both negative physical and psychological health effects on the women and children as well.

Access to biomass fuel will remain a challenge because of its growing demand for domestic use especially in the rural areas. Notably, Uganda is dominated by a rural population of more than $80 \%$ that rely on unprocessed biomass for cooking [26]. A study by Bamwesigye et al. [32] confirms that more than $90 \%$ of households in Uganda use firewood and charcoal fuel. Access to biomass will remain a challenge in Uganda since it has been estimated that $22 \%$ of the rural population have already experienced biomass shortfalls [54]. Similarly, in Southeast Asia, access to firewood is also a challenge. For instance due to scarcity of firewood, the rural households opted for inferior types of biomass resources such as leaves, twigs, rice straw and other crop residues [55]. Women being the primary users of household energy are therefore most adversely affected by lack of access to various energy sources including biomass $[2,6,46]$. Thus, the scarcity of biomass fuel implies that women will remain vulnerable to health risks associated with the collection of biomass fuel.

There are health concerns focusing on women which are attributed to the use of traditional cookstoves and biomass fuel. As earlier noted, traditional cookstoves are inefficient because they utilize a lot of biomass fuel, releasing too much smoke during combustion [7, 56]. Notably, women spend more time cooking and are more exposed to smoke than any other members in the household $[2,6,46]$. This study focused on the perspectives of women and they also highlighted some health concerns in relation to the use of traditional cookstoves and biomass fuel. Other studies have also confirmed the correlation between women health and the usage of biomass fuel in traditional cookstoves particularly in developing countries [23, 24, 42]. For instance, in Nigeria, research shows that women suffer from ailments arising from biomass use and health similar to cigarette smokers [57]. A study conducted on biomass energy in Congo found a prevalence of chronic obstructive pulmonary disease (COPD) among Congolese women exposed to particulate matter [22]. Studies conducted in Senegal and Kenya indicated that the use of biomass fuel from traditional cookstoves may affect the respiratory health of not only the users but the occupants of the homestead in general $[2,9]$. However, this does not imply that the use of ICS may not contribute to health issues especially if biomass is still used. Relatedly, there are studies indicating that there are no significant emissions between traditional and improved cookstoves and therefore no conclusive difference in the health impacts between the two stove types $[8,11]$. Similarly, in this study from the women's perspectives, there was no significant variation on the health impact from the use of traditional cookstoves and the use of ICS.

Improved cookstoves have several benefits which are not only related to health, but also social and economic gains that could motivate users to purchase them. In this study, the health benefits associated with use of ICS were stipulated. Studies have confirmed that the use of ICS leads to a reduction in emissions hence decreasing indoor air pollution [24, 58]. It has been noted that improved cookstoves cook faster and thus reduce incidences of domestic violence in homesteads which may occur when food is not prepared in time (12). Although as previously indicated, some studies dispute the fact that there is no variation in the health impact from the use of ICS and traditional cookstoves, and the benefits associated with the use of ICS are vital because they may encourage adoption in rural communities.

Women are most affected by exposure to smoke and they yearn for alternative cooking options such as outdoor cooking that can contribute to the reduction of indoor pollution $[2,6,59]$. Despite the health adversaries attributed to the use of traditional cookstoves, it is still noted that the majority of rural communities cannot easily adopt to other alternatives $[3,6]$. However, adoption of efficient cookstoves which usually begins at individual household level is hindered by a lack of technological know-how and experience in addition to behavior change of the communities [2]. Additionally, socio-economic as well as social-cultural factors which include household 
preferences and affordability have also hindered adoption [2]. It is for instance noted that peer influence plays a role in the adoption of improved cook stoves [20]. However, as noted in Senegal, the preference for cookstoves may not be the traditional type [2]. Women are shifting away from the traditional cookstoves in the rural homesteads because of lack of biomass fuel, albeit slowly.

This study has tried to link the use of biomass fuel to various health outcomes transcending the physical to the psychological status of women which hitherto has not been explored in that dimension. The study echoes the voices of women as the vulnerable group. Nonetheless, this study is not without limitations. It focused on the views of women that were using ICS and traditional cookstoves. Due to the patriarchal nature of most rural communities, women play the role of cooking and are more vulnerable to exposure to pollution. Men as income providers should have been interviewed to contribute to the perspectives of women on health concerns attributed to access and use of biomass fuel. This could also shed a light on why men as providers cannot set aside resources for purchasing energy to meet family needs which would reduce on the vulnerabilities exposed to women while gathering biomass fuel. Another limitation is that this study did not focus on unearthing health impacts before and after ICS adoption for the ICS users, which would have been imperative because people's memory may be skewed by their high expectations of the benefits of ICS.

\section{Conclusion}

Biomass fuel contributes to poor health in regard to its access and usage. Gathering of biomass fuel can lead to physical and psychological health challenges, while its usage contributes to indoor air pollution which may lead to ill health. Women bear the burden of not only ensuring access to biomass fuel, but also exposure to indoor pollution in most households in rural communities. Therefore, it is crucial for the government and other stakeholders such as the private sector, researchers and innovators, development practitioners, social justice activists to develop and encourage the use of alternative safer sources of energy and efficient cookstoves for rural homesteads. The ecological model would be appropriate to spearhead the adoption of initiatives towards the promotion of alternative safer sources of energy and more efficient cookstoves. This would be effective in changing mindsets, realigning relevant effective energy-oriented policies and initiatives if interpersonal, institutional, community and public policy factors are taken into consideration in relation to clean cooking.

\section{Acknowledgements}

The authors would like to thank the different respondents, Local Council members, opinion leaders, sub-county Development Officers and Chief Administrative Officers in the districts of study. Special acknowledgement goes to the Center for Integrated Research and Community Development Uganda, for the mentorship and support. Special thanks goes to the field Assistants for their contribution in data collection and also to Caroline Tuhwezeine Kumwesiga from Research and Education Network Uganda (RENU) for the professional language check.

\section{Authors' contributions}

Both authors were involved in the research design, data analysis, interpretation of results and manuscript writing. JK was in charge of drafting research tools, administering interviews, and observation checklists for data collection and also drafted the manuscript. FM was in charge of technical guidance during data analysis and manuscript review. Both authors read and approved the final manuscript.

\section{Funding}

The research had no special funding apart from the special contributions from the authors of this manuscript. Special thanks to my co-author for the support throughout this journey.

\section{Availability of supporting data}

The datasets used in this study are available from the corresponding author on reasonable time request.

\section{Declarations}

\section{Ethics approval and consent to participate}

Permission to conduct this study was sought from relevant administrative authorities at various levels in the study area. At the household level, consent to participate in the study was also sought.

\section{Consent for publication}

The authors declare that this manuscript has not been published, or accepted for publication or under editorial review for publication elsewhere and thus consent to publish this manuscript with the Energy, Sustainability and Society Journal.

\section{Competing interests}

The authors declare that there is no conflict of interest regarding the publication of this paper.

\section{Author details}

${ }^{1}$ Department of Biology, Kyambogo University, Kyambogo, P.O. Box 1, Kampala, Uganda. ${ }^{2}$ Institute of Human Settlements Studies, Ardhi University, P. O Box 35176, Dar es Salaam, Tanzania.

Received: 23 January 2021 Accepted: 21 October 2021

Published online: 08 November 2021

\section{References}

1. Lambe F, Jürisoo M, Wanjiru H, Senyagwa J (2015) Bringing clean, safe, affordable cooking energy to households across Africa: an agenda for action. The New Climate Economy, 1-32

2. Hooper LG, Yakou D, Assane N, Aldiouma D, Coralynn SS, Vincent SF et al (2018) Traditional cooking practices and preferences for stove features among women in rural Senegal: informing improved cookstove design and interventions. PLOS ONE 13:1-15. https://doi.org/10.1371/journal. pone.0206822

3. Putti VR, Tsan M, Mehta S, Kammila S (2015) The state of the global clean and improved cooking sector: Technical report 007/15. Washington DC

4. AFREA (2011) Wood-based biomass energy development for sub-saharan africa: issues and approaches. AFREA, Washington, DC

5. UNEP (2019) Review of woodfuel biomass production and utilization in Africa. UNEP, Nairobi 
6. FAO (2019) Building resilience through safe access to fuel and energy (SAFE): moving towards a comprehensive SAFE Framework. FAO, Rome. https://doi.org/10.18356/24df1c36-en

7. Mamuye F, Lemma B, Woldeamanuel T (2018) Emissions and fuel use performance of two improved stoves and determinants of their adoption in Dodola, southeastern Ethiopia. Sustain Environ Res 28:32-38. https:// doi.org/10.1016/.jseri.2017.09.003

8. Mitchell EJS, Ting Y, Allan J, Spracklen DV, Mcfiggans G, Coe H et al (2019) Pollutant emissions from improved cookstoves of the type used in Sub-Saharan Africa pollutant emissions from improved cookstoves of the type used in Sub-Saharan Africa. Combust Sci Technol. https://doi.org/10. 1080/00102202.2019.1614922

9. Jürisoo et al (2018) Beyond buying: the application of service design methodology to understand adoption of clean cookstoves in Kenya and Zambia. Energy Res Soc Sci 39:164-176. https://doi.org/10.1016/j.erss. 2017.11.023

10. MacCarty et al (2020) Stratification of particulate matter in a kitchen: A comparison of empirical to predicted concentrations and implications for cookstove emissions targets. Energy Sustain Dev 54:14-24. https://doi. org/10.1016/j.esd.2019.09.006

11. Rose Eilenberg S, Bilsback KR, Johnson M, Kodros JK, Lipsky EM, Naluwagga A et al (2018) Field measurements of solid-fuel cookstove emissions from uncontrolled cooking in China, Honduras, Uganda, and India. Atmos Environ 190:116-125. https://doi.org/10.1016/j.atmosenv.2018.06. 041

12. Lambe F, Jürisoo M, Wanjiru H, Senyagwa J (2015) Bringing clean, safe, affordable cooking energy to households across Africa: an agenda for action. Stockholm and Nairobi

13. WHO (2014) World health statistics 2014. WHO, Geneva

14. Putti VR, Tsan M, Mehta S, Kammila S (2015) The state of the global clean and improved cooking sector. ESMAP Tech Pap 007/15. Washington, DC

15. Mary Robinson Foundation Climate Justice (2012) Enabling women's development and empowerment through access to clean, affordable, sustainable energy. Mary Robinson Foundation Climate Justice, Dublin

16. GACC (2016) Gender-based violence in humanitarian settings: cookstoves and fuels, a systematic review of the evidence base. Global Alliance for Clean Cookstoves, Washington, DC

17. GACC (2015) Statistical snapshot: access to improved cookstoves and fuels and its impact on women's safety in crises. Global Alliance for Clean Cookstoves, Washington, DC

18. Guzmán JC, Khatiwada LK, Guzmán DB (2020) Improved cookstoves as a pathway between food preparation and reduced domestic violence in Uganda. World Dev Perspect 18:100202. https://doi.org/10.1016/j.wdp. 2020.100202

19. Monsivais P, Aggarwal A, Drewnowski A (2014) Time spent on home food preparation and indicators of healthy eating. Am J Prev Med 47:796-802. https://doi.org/10.1016/j.amepre.2014.07.033.Time

20. Beltramo T, Blalock G, Levine DI, Simons AM (2015) Does peer use influence adoption of efficient cookstoves? Evidence from a randomized controlled trial in Uganda. J Health Commun 20:55-66. https://doi.org/ 10.1080/10810730.2014.994244

21. MacCarty N, Bentson S, Cushman K, Au J, Li C, Murugan G et al (2020) Stratification of particulate matter in a kitchen: a comparison of empirical to predicted concentrations and implications for cookstove emissions targets. Energy Sustain Dev 54:14-24. https://doi.org/10.1016/j.esd.2019. 09.006

22. Mbelambela EP, Muchanga SMJ, Villanueva AF, Eitoku M, Yasumitsu-Lovell K, Hirota R et al (2020) Biomass energy, particulate matter (PM2.5), and the prevalence of chronic obstructive pulmonary disease (COPD) among Congolese women living near of a cement plant, in Kongo Central Province. Environ Sci Pollut Res 27:40706-40714. https://doi.org/10.1007/ s11356-020-10099-2

23. Das I, Jagger P, Yeatts K (2017) Biomass cooking fuels and health outcomes for women in Malawi. EcoHealth 14:7-19. https://doi.org/10.1007/ s10393-016-1190-0

24. Khatiwada LK (2016) Clean cookstoves for improving women's health: initial findings from rural Uganda

25. Levine DI, Beltramo T, Blalock G, Cotterman C, Simons AM (2018) What impedes efficient adoption of products? Evidence from randomized sales offers for fuel-efficient cookstoves in Uganda. J Eur Econ Assoc 16:1850-1880. https://doi.org/10.1093/jeea/jvx051
26. Price R (2017) "Clean" cooking energy in Uganda—technologies, impacts, and key barriers and enablers to market acceleration. K4D Help Rep

27. Diehl JC, Van Sprang S, Alexander J, Kersten W (2019) A scalable clean cooking stove matching the cooking habits of Ghana and Uganda. In: GHTC 2018-IEEE global humanitarian technology conference, proceedings, IEEE, p 1-8. https://doi.org/10.1109/GHTC.2018.8601916

28. Jagoe K, Rossanese M, Charron D, Rouse J, Waweru F, Waruguru MA et al (2020) Sharing the burden: shifts in family time use, agency and gender dynamics after introduction of new cookstoves in rural Kenya. Energy Res Soc Sci. https://doi.org/10.1016/j.erss.2019.101413

29. Choudhuri P, Desai S (2020) Gender inequalities and household fuel choice in India. J Clean Prod 265:121487. https://doi.org/10.1016/j.jclepro. 2020.121487

30. Das I, Klug T, Krishnapriya PP, Plutshack V, Saparapa R, Scott S et al (2020) A virtuous cycle? Reviewing the evidence on women's empowerment and energy access, frameworks, metrics and methods

31. Jagger $P$, Kittner $N$ (2017) Deforestation and biomass fuel dynamics in Uganda. Biomass Bioenergy 105:1-9. https://doi.org/10.1016/j.biombioe. 2017.06.005

32. Bamwesigye D, Kupec P, Chekuimo G, Pavlis J, Asamoah O, Darkwah SA et al (2020) Charcoal and wood biomass utilization in Uganda: the socioeconomic and environmental dynamics and implications. Sustainability 12:8337. https://doi.org/10.3390/su12208337

33. Fashina A, Mundu M, Akiyode O, Abdullah L, Sanni D, Ounyesiga L (2018) The drivers and barriers of renewable energy applications and development in Uganda: a review. Clean Technol 1:9-39. https://doi.org/10.3390/ cleantechnol1010003

34. Adeyemi K, Asere A (2014) A review of the energy situation in Uganda. Energy Explor Exploit 4:2250-3153

35. Kureeba D (2014) Firewood collection in the Bukaleba forest reserve. In: Hall R (ed) A global overview of wood bioenergy: production, consumption, trends and impacts. Global Forest Coalition, Kampala

36. Okello C, Pindozzi S, Faugno S, Boccia L (2013) Development of bioenergy technologies in Uganda: a review of progress. Renew Sustain Energy Rev 18:55-63. https://doi.org/10.1016/j.rser.2012.10.004

37. Namaalwa J, Sankhayan PL, Hofstad O (2007) A dynamic bio-economic model for analyzing deforestation and degradation: an application to woodlands in Uganda. Forest Policy Econ 9:479-495. https://doi.org/10. 1016/j.forpol.2006.01.001

38. World Health Organisation (2018) Household air pollution and health World Health Organisation, Geneva

39. Zahno M, Michaelowa K, Dasgupta P, Sachdeva I (2020) Health awareness and the transition towards clean cooking fuels: evidence from Rajasthan. PLOS ONE 15:1-26. https://doi.org/10.1371/journal.pone.0231931

40. Austin K, Mejia MT (2017) Household air pollution as a silent killer: women's status and solid fuel use in developing nations. Popul Environ. https://doi.org/10.1007/s11111-017-0269-z

41. Mcleroy KR, Bibeau D, Steckler A, Glanz K (1988) An ecological perspective on health promotion programs. Health Educ Behav 15:351-377. https://doi.org/10.1177/109019818801500401

42. Musthafa SNAM, Leh OLH, Omar D, Karuppannan S (2015) Theoretical review on environmental health in relation to neighbourhood planning and human physical activity. Procedia Soc Behav Sci 201:325-332. https:// doi.org/10.1016/j.sbspro.2015.08.182

43. Stokols D (1992) Establishing and maintaining healthy environments: toward a social ecology of health promotion. Am Psychol 47:6-22. https://doi.org/10.1037/0003-066X.47.1.6

44. Stokols D (1996) Translating social ecological theory into guidelines for community health promotion. Am J Health Promot 10:282-298. https:// doi.org/10.4278/0890-1171-10.4.282

45. Golden SD, McLeroy KR, Green LW, Earp JAL, Lieberman LD (2015) Upending the social ecological model to guide health promotion efforts toward policy and environmental change. Health Educ Behav 42:8-14. https:// doi.org/10.1177/1090198115575098

46. GVEP International (2012) Global alliance for clean cookstoves: Uganda market assessment intervention options. GVEP International, Kampala

47. Bronfenbrenner U (1992) Ecological systems theory. Six theories of child development: revised formulations and current issues. Jessica Kingsley Publishers, London

48. Yamane T (1967) Statistics: an introductory analysis, 2nd edn. Harper and Row, New York 
49. Gebrecherkos AB, Weldeslasie TB (2020) Adoption determinants of improved cookstove among rural households: the case of Benishngul Gumuz. Int J Sci Res Publ 10:726-731. https://doi.org/10.29322/IJSRP.10. 09.2020.p10587

50. UBOS (2017) Education: a means for population transformation. UBOS, Kampala

51. World Bank Group (2016) The Uganda Poverty Assessment Report 2016. World Bank Group, Washington, D.C

52. Taylor ET, Nakai S (2012) The levels of toxic air pollutants in kitchens with traditional stoves in Rural Sierra Leone. J Environ Prot 3:1353-1363

53. Nakora N, Byamugisha D, Birungi G (2020) Indoor air quality in rural Southwestern Uganda: particulate matter, heavy metals and carbon monoxide in kitchens using charcoal fuel in Mbarara Municipality. SN Appl Sci 2:1-16. https://doi.org/10.1007/s42452-020-03800-0

54. GACC (2017) Comparative analysis of fuels for cooking: life cycle environmental impacts and economic and social considerations. Global Alliance for Clean Cookstoves, Washington, DC

55. Hassan MK, Halder P, Pelkonen P, Pappinen A (2013) Rural households' preferences and attitudes towards biomass fuels_-results from a comprehensive field survey in Bangladesh. Energy Sustain Soc 3:1-14. https:// doi.org/10.1186/2192-0567-3-24

56. Bede-ojimadu O, Orisakwe OE (2020) Exposure to wood smoke and associated health effects in Sub-Saharan Africa: a systematic review. Ann Glob Health 86:1-27

57. Olugboji O (2020) Women in Nigeria should not have to risk their health to feed others. World Pulse, p 1-5

58. Bailis R, Drigo R, Ghilardi A, Masera O (2015) The carbon footprint of traditional woodfuels. Nat Clim Change. https://doi.org/10.1038/NCLIMATE24 91

59. Langbein J (2017) Firewood, smoke and respiratory diseases in developing countries- the neglected role of outdoor cooking. PLOS ONE 12:1-14. https://doi.org/10.1371/journal.pone.0178631

\section{Publisher's Note}

Springer Nature remains neutral with regard to jurisdictional claims in published maps and institutional affiliations.

Ready to submit your research? Choose BMC and benefit from:

- fast, convenient online submission

- thorough peer review by experienced researchers in your field

- rapid publication on acceptance

- support for research data, including large and complex data types

- gold Open Access which fosters wider collaboration and increased citations

- maximum visibility for your research: over 100M website views per year

At $\mathrm{BMC}$, research is always in progress.

Learn more biomedcentral.com/submissions 